\title{
Erratum
}

\section{Erratum to: Once more on Coulomb-nuclear interference}

\author{
Vladimir A. Petrov ${ }^{\mathrm{a}}$
}

Logunov Institute for High Energy Physics, NRC Kurchatov Institute, Protvino, Russian Federation

Received: 8 May 2018 / Accepted: 10 May 2018 / Published online: 25 May 2018

(C) The Author(s) 2018

Eur. Phys. J. C (2018) 78:221

https://doi.org/10.1140/epjc/s10052-018-5716-1

In Eqs. (17) and (18) terms $(8 \pi s \alpha) / t$ should be read as $(8 \pi s \alpha) F^{2}(t) / t$.

Open Access This article is distributed under the terms of the Creative Commons Attribution 4.0 International License (http://creativecomm ons.org/licenses/by/4.0/), which permits unrestricted use, distribution, and reproduction in any medium, provided you give appropriate credit to the original author(s) and the source, provide a link to the Creative Commons license, and indicate if changes were made.

Funded by $\mathrm{SCOAP}^{3}$.

The online version of the original article can be found under https:// doi.org/10.1140/epjc/s10052-018-5716-1.

a e-mail: vladimir.petrov@ihep.ru 